\title{
Anxiety, Depression, and Quality of Life: A Long-Term Follow-Up Study of Patients with Persisting Concussion Symptoms
}

\author{
Corinne Doroszkiewicz, David Gold,2 Robin Green,,3 Maria Carmela Tartaglia,, \\ Jin $\mathrm{Ma}^{6}$ and Charles H. Tator ${ }^{1,4}$
}

\begin{abstract}
Persisting concussion symptoms (PCS) can last for months, years, or indefinitely and affect a considerable number of concussion patients. The objectives of this study were to evaluate the prevalence of clinical symptoms of anxiety and depression and the relationship between PCS and quality of life in patients examined at the Canadian Concussion Centre. The Depression and Anxiety Stress Scale-42 (DASS-42) and the World Health Organization Quality of Life AssessmentBREF (WHOQOL-BREF) were sent to 526 adult patients diagnosed with PCS. Median with interquartile range follow-up time was 5 (4-7) years. Of the 105 respondents, $35.2 \%$ displayed mild or greater symptoms of anxiety, depression, or both. Importantly, the number of previous concussions was correlated with elevations on the DASS-42 Anxiety $(p=0.030)$ and Depression $(p=0.018)$ subscale scores, suggesting an acquired cause of symptoms. Patients with clinical elevations of depression, anxiety, or both exhibited poorer mean WHOQOL-BREF scores in each domain $(p<0.001)$ compared to those who scored in the normal range on the DASS-42. These findings indicate that depression and anxiety in PCS can endure for years and are associated with diminished quality of life. Consequently, depression and anxiety should be identified and treated early in PCS populations in order to optimize recovery. Although the underlying etiology of depression and anxiety cannot be ascertained with certainty in the present study, the association between depression and anxiety and the number of concussions may indicate an organic explanation. In the future, quality-of-life measures should be incorporated into treatment and research in PCS to improve intervention strategies and enhance understanding of the trajectory of recovery in this population.
\end{abstract}

Keywords: anxiety; DASS-42; depression; post-concussion syndrome; quality of life; WHOQOL-BREF

\section{Introduction}

A PPROXIMATELY $75 \%$ of persons will recover from a concussion within 7-10 days, although some take longer, whereas others never recover. ${ }^{1,2}$ There is considerable variability in the recovery rate and completeness of recovery. ${ }^{3}$ The literature reveals variable estimates of the prevalence of prolonged symptoms of concussion-commonly referred to as post-concussion syndrome-ranging from $5 \%$ to $50 \%{ }^{5}$ The most commonly reported rate is $10-15 \% .^{1,6,7}$ These disparate estimates may be attributable to differing diagnostic criteria for the enduring effects of concussion. In the absence of a reliable imaging or body fluid biomarker, clinical signs and symptoms remain the criterion for the diagnosis of this condition, which we have chosen to call persisting concussion symptoms (PCS) and which we define as three or more symptoms persisting for more than 1 month after concussion, a definition we have previously reported. ${ }^{1}$

In contrast, The International Classification of Diseases, Tenth Revision requires three symptoms or more from a restricted list of symptoms including headache, dizziness, fatigue, irritability, insomnia, concentration difficulty, memory difficulty, and reduced tolerance to stress, emotional excitement, or alcohol. ${ }^{8}$ However, the

\footnotetext{
${ }^{1}$ Canadian Concussion Center, Toronto, Ontario, Canada.

${ }^{2}$ Neuropsychology Clinic, Krembil Neuroscience Network, ${ }^{4}$ Division of Neurosurgery, ${ }^{5}$ Division of Neurology, Toronto Western Hospital, University Health Network, Toronto, Ontario, Canada.

${ }^{3}$ Toronto Rehabilitation Institute, ${ }^{6}$ Biostatistics Research Unit, University Health Network, Toronto, Ontario, Canada.

(c) Corinne Doroszkiewicz et al., 2020; Published by Mary Ann Liebert, Inc. This Open Access article is distributed under the terms of the Creative Commons Attribution Noncommercial License (http://creativecommons.org/licenses/by-nc/4.0/) which permits any noncommercial use, distribution, and reproduction in any medium, provided the original author(s) and the source are credited.
} 
Diagnostic and Statistical Manual of Mental Disorders, Fourth Edition (DSM-IV) requires three or more symptoms from an overlapping list, including fatigue, headache, personality change, apathy, depression, or anxiety, and requires these symptoms to last $\geq 3$ months after injury. ${ }^{9}$ The DSM-IV further requires the presence of cognitive deficits in attention or memory and a significant decline in social and/or occupational functioning. ${ }^{9}$ The Diagnostic and Statistical Manual of Mental Disorders, Fifth Edition (DSM-V) replaced the term PCS and created a new term for the condition called "major or mild neurocognitive disorder due to traumatic brain injury," consistent with a general movement away from assumptions regarding the presence of a syndrome and/or an underlying aetiology of the symptoms. ${ }^{10}$

Further, the DSM-V only recognizes patients with loss of consciousness, disorientation, amnesia, hemiparesis, or abnormal neuroimaging, ${ }^{10}$ thereby incorporating more severe neurological events. The 5th International Concussion Consensus Conference in Sport did not provide a list of required symptoms for a diagnosis of PCS, but rather defines it as a "constellation of non-specific symptoms related to traumatic brain injury" that need to persist for "10-14 days in adults and 4 weeks in children" to qualify for a diagnosis of "persisting symptoms of concussion." 11 Thus, there is a lack of consensus with respect to the list of eligible symptoms and duration of PCS.

The most common persisting symptoms of concussion are headaches, memory deficits, concentration difficulties, imbalance, dizziness, fatigue, and nausea. ${ }^{1}$ Psychosocial contributions include greater functional limitations (contributing to anger and frustration), reduced participation in daily living, including social and recreational activities, poorer quality of life, and the experience of loss. ${ }^{12,13}$ Across studies, reported prevalence rates for depression after concussion have been wide ranging, from $14 \%$ to $29 \%$ in some studies, ${ }^{14,15}$ to $35 \%$ in others, ${ }^{13,16}$ and from $14 \%$ to $61 \%$ in still another. ${ }^{17}$ Similarly, the estimated prevalence of anxiety disorders in PCS ranges from $18 \%$ to $60 \%,{ }^{18,19}$ depending on diagnostic criteria, population, and timing of assessment. ${ }^{20}$ Frequently cited pre-injury predictors of depression in patients with PCS include younger age ${ }^{14,21}$ pre-morbid psychiatric illness, ${ }^{13,16,22}$ female sex, ${ }^{23,24}$ and increased number of previous concussions. ${ }^{1,25}$ Pre-injury predictors of anxiety in PCS include older age, ${ }^{26,27}$ female sex,${ }^{27-29}$ as well as pre-morbid psychiatric illness. ${ }^{21}$

Depressive symptoms in PCS patients are associated with worse functional outcomes and poorer cognitive performance. ${ }^{13}$ Studies have also shown that the risk of suicide in concussion patients is 3 times the population norm, regardless of patient demographics and independent of past psychiatric conditions. ${ }^{30}$ Persisting symptoms of depression and anxiety not only affect the patient, but also have economic implications as a result of delayed return to work, diminished productivity at work, reduced rates of labor participation, and increased healthcare and welfare expenditures. ${ }^{31}$

With regard to quality of life (QOL), only a small number of studies have examined this outcome to date in PCS patients. These studies, predominantly based in Europe, assessed QOL in adult ${ }^{32}$ and pediatric patients, ${ }^{33}$ as well as Short Form 36 (SF-36) scores in adults, ${ }^{34}$ and found that, generally, patients with PCS have lower SF-36 scores compared to concussion patients without PCS. ${ }^{32}$ However, to our knowledge, no studies have examined QOL in patients with prolonged symptoms of concussion in a North American sample, and little is known about the associations between QOL and symptoms of depression and/or anxiety in PCS. Given the complexity of PCS, the paucity of definitive treatments, and an incomplete understanding of the pathophysiology of enduring symptoms of concussion, it is important to evaluate QOL in these patients. Such measures represent an important outcome after concussion, given that they provide data on recovery patterns, frequency, nature, severity, and duration of the functional consequences after injury. ${ }^{20}$ These measures are essential in the evaluation of functional recovery, costs, and return to work and play. ${ }^{20}$

The present study sought to address some of these gaps in the literature through a survey of 105 patients in the community with PCS referred to the Canadian Concussion Centre (CCC) for consultation. The patient population in this study represents a very specific subset of patients with PCS given that this Centre focuses on PCS and has long wait times.

The three main objectives of the study were to: 1) determine the prevalence and severity of depression and anxiety symptoms in PCS patients as measured through the Depression and Anxiety Stress Scale-42 (DASS-42 ${ }^{35}$ ); 2) evaluate how symptoms of depression and anxiety in PCS relate to age, sex, mechanism of concussion injury, and number of previous concussions; and 3) determine the correlation of DASS- $42^{35}$ scores as a general measure of distress to QOL in PCS.

We hypothesized that depression and anxiety are significant issues in PCS and that factors such as age, sex, mechanism of injury, and number of previous concussions influence the prevalence of depression and anxiety in PCS, and that depression and anxiety in PCS influence QOL.

\section{Methods \\ Patient population}

Participants were recruited from a clinical database of 840 PCS patients who were seen in consultation by the senior author (C.H.T., a neurosurgeon) between 1997 and 2018 at the CCC. This study was approved by the University Health Network Research Ethics Board, and each of the questionnaire respondents provided written informed consent before participation. For those participants under the age of 18 , consent was obtained from a parent or guardian in addition to the consent of the participant. All patients in the clinical database had been referred to the CCC by their family physician or another specialist. Elapsed time between referral to the CCC and examination varied from 1 to 4 months. Persons referred to the CCC do not represent the entire spectrum of PCS patients, but rather those with prolonged recovery that required specialized management after assessment in the community.

Participants in the database were eligible for the current study if they: 1) had received a clinical diagnosis of concussion at the CCC, based on the definition of concussion prescribed by the International Consensus on Concussion in Sport, ${ }^{11}$ and 2) were suffering from persisting symptoms of concussion upon presentation at the CCC. Some participants had sustained more than one concussion. In the present study, we considered the most recent concussion recorded in their clinical history, which usually precipitated their visit to the $\mathrm{CCC}$, as the index concussion. Not all eligible participants had magnetic resonance imaging (MRI) or computed tomography (CT) imaging; however, those who did had normal findings without the presence of any other underlying diagnoses such as hemorrhage, stroke, or tumor.

Patients were ineligible if there was any of the following: 1) a clinical history of an underlying neurological disorder, or a psychiatric disorder apart from anxiety or depression; 2) abnormal MRI or CT findings suggesting a more severe brain injury, such as contusion or hemorrhage, or had a stroke or tumor; 3) involvement in pending litigation, given how some authors suggest that these patients are more likely to report a larger number of symptoms and exaggerate the severity of their symptoms ${ }^{36}$; 4) extracerebral 
injuries such as skull or facial fractures; or 5) incomplete demographic and/or imaging information. Required demographic information included age, sex, mechanism of injury, and number of previous concussions.

Based on these criteria, 314 patients were ineligible (Table 1), and thus 526 participants from the clinical database were eligible for inclusion in the current study. These 526 patients were mailed the study questionnaire (see below), and of these, 120 patients provided complete information by the study cut-off period (10 weeks). From the 120 questionnaires received by the study cutoff period, 15 additional questionnaires were excluded because of new information about litigation or skull fracture (Fig. 1). Thus, 105 patients were included in the final sample for the study (Fig. 1). When conducting the (WHOQOL-BREF) ${ }^{37}$ analysis, we excluded an additional 5 patients because of incomplete WHOQOL-BREF ${ }^{37}$ questionnaire data, resulting in a total of 100 patients being included in the WHOQOL-BREF ${ }^{37}$ portion of the analysis (Fig. 1).

\section{Measures}

Depression and Anxiety Stress Scale-42. The DASS- $42^{35}$ is a 42-item self-report questionnaire, which consists of 42 negative emotional symptoms and is available in the public domain. ${ }^{35} \mathrm{Re}-$ spondents are asked to rate the extent to which they have experienced each symptom on the scale over the previous week on a 4-point severity scale. ${ }^{35}$ In keeping with DASS- $42^{35}$ guidelines, patients scoring above the normal range for symptom severityanywhere from mild to extremely severe-were classified as endorsing the symptom. The DASS $-42^{35}$ has demonstrated good reliability and validity in clinical and non-clinical populations, including concussion. ${ }^{38}$ The DASS $-42^{35}$ corresponds to the tri-

Table 1. Exclusions $(N=329)$

\begin{tabular}{|c|c|c|}
\hline Exclusion type & $\begin{array}{l}\text { No. of patients } \\
\text { excluded }(\mathrm{n})\end{array}$ & $\begin{array}{l}\text { Percentage } \\
\text { of excluded } \\
\text { patients }\end{array}$ \\
\hline Abnormal CT, MRI, SPECT & 106 & 32.2 \\
\hline $\begin{array}{l}\text { Other (missing info, no } \\
\text { concussion diagnosis, unclear } \\
\text { MRI findings, failure of } \\
\text { patient to attend follow-up } \\
\text { appointment, etc.) }\end{array}$ & 53 & 16.1 \\
\hline Extracerebral injuries & 53 & 16.1 \\
\hline Litigation & 31 & 9.4 \\
\hline $\begin{array}{l}\text { No PCS diagnosis because } \\
<3 \text { symptoms }\end{array}$ & 28 & 8.5 \\
\hline $\begin{array}{l}\text { No PCS diagnosis because } \\
<1 \text { month of follow-up }\end{array}$ & 27 & 8.2 \\
\hline $\begin{array}{l}\text { Other lesion present: arachnoid } \\
\text { cyst, brain tumor, cerebral } \\
\text { contusion, craniotomy, IHH, } \\
\text { stroke }\end{array}$ & 16 & 4.9 \\
\hline $\begin{array}{l}\text { Other psychiatric illness besides } \\
\text { anxiety and depression }\end{array}$ & 13 & 4.0 \\
\hline Addiction, drug use & 2 & 0.6 \\
\hline Total & 329 & 100 \\
\hline
\end{tabular}

Table includes patients who were initially excluded before the questionnaire package was mailed $(n=314)$ as well at the additional exclusions that were made upon receipt of the questionnaire package $(n=15)$.

CT, computed tomography; MRI, magnetic resonance imaging; SPECT, single-photon emission computed tomography; IIH, idiopathic intracranial hypertension; PCS, post-concussion syndrome.

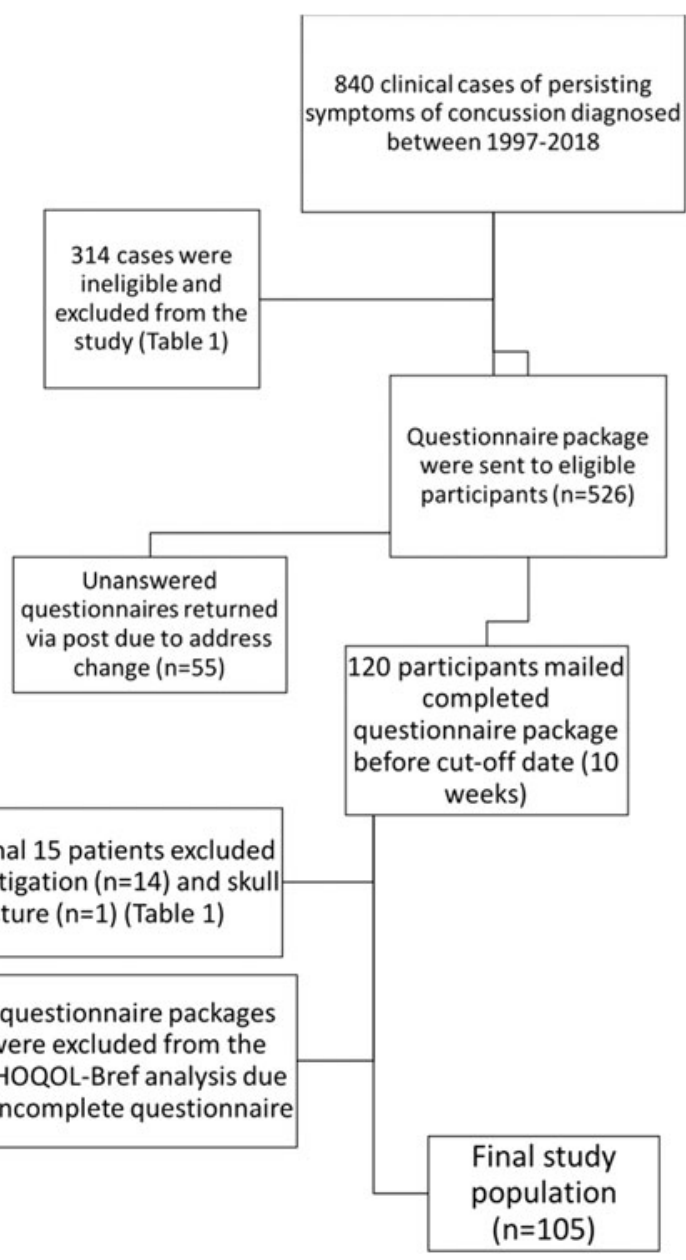

FIG. 1. Flowchart outlining study participant selection. A total of 329 patients were excluded from the initial population of 840 patients. The total number of patients included in the study was 105. WHOQOL-BREF, World Health Organization Quality of Life Assessment-BREF.

partite model of anxiety and depression, ${ }^{39}$ which suggests that anxiety and depression possess unique features as well as common ones. The DASS $-42^{35}$ is unique because of its ability to assess mood disturbance without the inclusion of somatic items, such as sleep problems and loss of appetite, which may be better explained by a medical condition rather than a mood disturbance. ${ }^{40}$ The structure of the DASS- $42^{35}$ presumes that depression and anxiety have a common, non-specific factor of general distress, like irritability and nervous tension. ${ }^{40}$ Thus, the total score is a meaningful indicator of a patient's general mood distress.

However, the DASS $-42^{35}$ also provides meaningful domain scores for depression (low mood, motivation, and self-esteem), anxiety (physiological arousal, perceived panic, and fear), and stress (difficulty relaxing, nervous arousal, and being easily upset/agitated). ${ }^{40}$ The Total DASS- $42^{35}$ score was the summation of each of the three DASS- $42^{35}$ domain scores (depression, anxiety, and stress).

World Health Organization Quality of Life-BREF. The WHOQOL-BREF $^{37}$ is a 26-item version derived from the WHOQOL-100, and is a cross-culturally valid assessment of wellbeing. ${ }^{41}$ The WHOQOL-BREF ${ }^{37}$ contains two questions that are 
not included in the overall score, but act as a measure of overall QOL. The first question asks, "How would you rate your quality of life?" with a rating of 1 indicating "very poor" and a rating of 5 indicating "very good." The second question asks, "How satisfied are you with your health?" with a rating of 1 indicating "very poor" and a rating of 5 indicating "very good." The remaining 24 items of satisfaction are divided into four domains. The domains cover physical health, psychological health, social relationships, and the environment. Each item is rated on a 5-point Likert scale. Raw scores from each domain are transformed according to scoring guidelines. Domain scores are scaled in a positive direction, with higher scores denoting a higher QOL.

The WHOQOL-BREF ${ }^{37}$ has been validated as having excellent psychometric properties of reliability (internal consistency) and is a valid, cross-cultural assessment of quality of physical, psychological, social, and environmental health. ${ }^{41}$ Mean overall WHOQOL$\mathrm{BREF}^{37}$ score was calculated by averaging the four domain scores (physical health, psychological health, social relationships, and environment) for each patient.

\section{Procedure}

The questionnaire package was mailed to eligible participants and consisted of: 1) a letter explaining the purpose of the study; 2) a consent form; 3) the DASS- $42^{35}$; 4) the WHOQOL-BREF ${ }^{37}$; and 5) a pre-paid postage return envelope. Participants were invited to complete these documents and mail them back to the CCC within 4 weeks of receiving them. Instructions regarding completion of each component were specified on each assessment measure. Returns were accepted up to 10 weeks after they were mailed out, and packages received beyond the cut-off date were not included in the study.

\section{Statistical analysis}

Descriptive statistics were summarized by frequencies and proportions for categorical data, and means and standard deviation (SD), or medians and interquartile ranges (IQRs), as appropriate, for continuous variables. The chi-square test was used to compare the categorical variables: sex, mechanism of injury, and number of previous concussions, and the Student $t$-test was used for continuous variables: current age between respondents and non-respondents.
Fisher's exact test was used for the comparison of DASS- $42^{35}$ depression and anxiety symptom severity according to categorical variables. Kruskal-Wallis' rank-sum test was used to assess the medians difference of DASS- $42^{35}$ depression, anxiety, stress, and total score between each categorical variables. One-way analysis of variance was used to compare the mean difference of WHOQOLBREF. ${ }^{37}$ Boxplots were generated to visualize the difference of DASS $-42^{35}$ score between the number of previous concussions. Scatterplots and a Spearman correlation coefficient were performed to evaluate the relationship between the DASS $-42^{35}$ score and WHOQOL-BREF ${ }^{37}$ score.

Statistical analyses were performed using R software (version 3.6.0; R Foundation for Statistical Computing, Vienna, Austria), and descriptive statistics were performed using the "tableone package." Statistical significance was set at a two-sided level of 0.05 .

\section{Results}

\section{Comparison of respondent and total eligible populations}

Table 2 compares the demographics of respondents with nonrespondents. No differences were found in mean age at the time of concussion between the respondent and non-respondent populations $(p=0.078)$. Respondents did not differ from non-respondents in terms of patient sex $(p=0.313)$. Table 2 shows that respondents were more likely to sustain their concussion as a result of a fall compared to a motor vehicle collision, sports and recreation injury, or strike by object $(p=0.045)$. There were no differences in the number of previous concussions acquired by respondents compared to non-respondents $(p=0.462)$.

\section{Depression and Anxiety Stress Scale-42 outcomes}

Thirty-seven (35.2\%) patients in the respondent population had clinically elevated symptoms of depression, anxiety, or both according to the DASS- $42,{ }^{35}$ defined as clinically elevated beyond the normal range, but ranged from mild to extremely severe. Eight (7.6\%) patients had symptoms of depression alone, 8 (7.6\%) had symptoms of anxiety alone, and 21 (20\%) patients

Table 2. Comparison of Patients Who Responded to Questionnaire Package $(N=$ io5) with Those Who Did Not Respond $(N=42$ I $)$

\begin{tabular}{|c|c|c|c|c|}
\hline & & No response $(\mathrm{n}=421)$ & Response received $(\mathrm{n}=105)$ & $\mathrm{p}$ value \\
\hline \multicolumn{2}{|c|}{ Age at the time of concussion, years, mean (SD) } & $30.57(14.7)$ & $33.46(15.9)$ & 0.078 \\
\hline \multirow{2}{*}{ Sex, $n(\%)$} & Male & $198(47.0)$ & $43(41.0)$ & 0.313 \\
\hline & Female & $223(53.0)$ & $62(59.0)$ & \\
\hline \multirow[t]{4}{*}{ Mechanism of injury, $n(\%)$} & Fall & $57(13.5)$ & $25(23.8)$ & $0.045^{*}$ \\
\hline & MVC & $70(16.6)$ & $12(11.4)$ & \\
\hline & $S \& R$ & $225(53.4)$ & $55(52.4)$ & \\
\hline & SO & $69(16.4)$ & $13(12.4)$ & \\
\hline \multirow[t]{3}{*}{ No. of previous concussions, $n(\%)$} & 0 & $104(25.3)$ & $32(31.4)$ & 0.462 \\
\hline & 1 & $88(21.4)$ & $20(19.6)$ & \\
\hline & $2+$ & $219(53.3)$ & $50(49.0)$ & \\
\hline
\end{tabular}

Demographic comparison of patients who responded to the questionnaire package $(n=105)$ with those who did not $(n=421)$.

Respondent and non-respondent groups differed according to mean age and mechanism of injury. Patients who responded to the study questionnaire package were, on average, older in comparison to those who did not respond.

*A greater percentage of patients who sustained their concussion as the result of a fall were represented in the respondent population in comparison to those who did not respond. No differences were found between the respondent and non-respondent populations according to patient sex and number of previous concussions.

MVC, motor vehicle collision; S \& R, sports and recreation; SO, struck by object. 
had symptoms of both depression and anxiety. Thus, the majority of patients in this population did not endorse elevated symptoms of depression or anxiety and scored in the normal range on the DASS $-42^{35}(n=68 ; 64.8 \%)$. We elected to focus on the anxiety and depression subscales, but it should be noted that we included the stress score in the total DASS- $42^{35}$ score analysis below. According to clinical chart history, 10 patients in the respondent population had a history of depression and anxiety that pre-dated their concussion and were included in the analysis. Of these 10, 4 had elevated symptoms of depression alone, 2 had elevated symptoms of depression and anxiety, and 4 respondents scored in the normal range for depression and anxiety. Table 3 provides an overview of other PCS symptoms that respondents with elevated DASS $-42^{35}$ scores self-reported as currently being experienced.
Depression and Anxiety Stress Scale-42 symptom severity and score in relation to patient age, sex, mechanism of injury, and number of previous concussions

No differences were found with respect to patient sex for DASS$42^{35}$ depression subscale median scores $(p=0.777)$, DASS $-42^{35}$ anxiety subscale scores $(p=0.235)$, and DASS $-42^{35}$ total score ( $p=0.325$; Table 4). Likewise, we found no association between mechanism of injury and DASS- $42^{35}$ depression subscale median score $(p=0.959)$, DASS $-42^{35}$ anxiety subscale median score $(p=0.953)$, and DASS $-42^{35}$ total score $(p=0.985$; Table 4$)$.

The increased number of previous concussions was correlated with an increased median score on each of the depression $(p=0.018)$, anxiety $(p=0.030)$, and stress $(p=0.010)$ DASS $-42^{35}$

Table 3. Other Currently Experienced Symptoms in PCS Patients with Symptoms of Depression Alone, Anxiety Alone, Depression, and Anxiety and All Patients with Either Depression and/or AnXiety $(N=37)$

\begin{tabular}{|c|c|c|c|c|}
\hline Symptom type & $\begin{array}{c}\text { Present in patients with } \\
\text { DASS-42 symptoms of } \\
\text { depression only }(\mathrm{n}=8) \\
\mathrm{n}(\%)\end{array}$ & $\begin{array}{c}\text { Present in patients with } \\
\text { DASS-42 symptoms of } \\
\text { anxiety only }(\mathrm{n}=8) \\
\mathrm{n}(\%)\end{array}$ & $\begin{array}{l}\text { Present in patients with } \\
\text { DASS-42 symptoms of } \\
\text { depression and anxiety } \\
(\mathrm{n}=21) \\
\mathrm{n}(\%)\end{array}$ & $\begin{array}{l}\text { Present in patients with } \\
\text { DASS-42 symptoms of anxiety, } \\
\text { depression, or both } \\
(\mathrm{n}=37) \\
\mathrm{n}(\%)\end{array}$ \\
\hline Imbalance & $4(50)$ & $3(37.5)$ & $6(28.6)$ & $13(35.1)$ \\
\hline Blurred vision & $2(25)$ & $0(0)$ & $4(19.0)$ & $6(16.2)$ \\
\hline Difficulty concentrating & $5(62.5)$ & $5(62.5)$ & $13(61.9)$ & $23(62.2)$ \\
\hline Confusion & $2(25.0)$ & $1(12.5)$ & $8(38.1)$ & $11(29.7)$ \\
\hline Dazed & $2(25.0)$ & $0(0)$ & $3(14.3)$ & $5(13.5)$ \\
\hline Disorientation & $2(25.0)$ & $1(12.5)$ & $4(19.0)$ & $7(18.9)$ \\
\hline Dizziness & $4(50.0)$ & $0(0)$ & $8(38.1)$ & $12(32.4)$ \\
\hline "Don't feel right" & $5(62.5)$ & $2(25.0)$ & $9(42.9)$ & $16(43.2)$ \\
\hline Double vision & $1(12.5)$ & $0(0)$ & $2(9.5)$ & $3(8.1)$ \\
\hline Fatigue & $5(62.5)$ & $2(25.0)$ & $13(61.9)$ & $20(54.1)$ \\
\hline Feeling slowed down & $4(50.0)$ & $1(12.5)$ & $7(33.3)$ & $12(32.4)$ \\
\hline Frustration & $3(37.5)$ & $3(37.5)$ & $10(47.6)$ & $16(43.2)$ \\
\hline Headache & $5(62.5)$ & $5(62.5)$ & $12(57.1)$ & $22(59.5)$ \\
\hline $\begin{array}{l}\text { Increased sensitivity } \\
\text { to alcohol }\end{array}$ & $2(25.0)$ & $1(12.5)$ & $6(28.6)$ & $9(24.3)$ \\
\hline Irritability & $6(75.0)$ & $1(12.5)$ & $11(52.4)$ & $18(48.6)$ \\
\hline Insomnia & $3(37.5)$ & $2(25.0)$ & $6(28.6)$ & $11(29.7)$ \\
\hline Lightheaded & $3(37.5)$ & $2(25.0)$ & $7(33.3)$ & $12(32.4)$ \\
\hline Loss of appetite & $0(0)$ & $1(12.5)$ & $3(14.3)$ & $4(10.8)$ \\
\hline $\begin{array}{l}\text { Difficulty remembering } \\
\text { recent events }\end{array}$ & $2(25.0)$ & $4(50.0)$ & $12(57.1)$ & $18(48.6)$ \\
\hline $\begin{array}{l}\text { Difficulty remembering } \\
\text { remote events }\end{array}$ & $3(37.5)$ & $2(25.0)$ & $6(28.6)$ & $11(29.7)$ \\
\hline Feeling in a fog & $3(37.5)$ & $1(12.5)$ & $6(28.6)$ & $10(27.0)$ \\
\hline Nausea & $3(37.5)$ & $3(37.5)$ & $6(28.6)$ & $12(32.4)$ \\
\hline Neck pain & $6(75.0)$ & $2(25.0)$ & $10(47.6)$ & $18(48.6)$ \\
\hline Numbness & $1(12.5)$ & $1(12.5)$ & $5(23.8)$ & 7 (18.9) \\
\hline Panic attacks & $1(12.5)$ & $1(12.5$ & $8(38.1)$ & $10(27.0)$ \\
\hline Personality changes & $3(37.5)$ & $0(0)$ & $6(28.6)$ & $9(24.3)$ \\
\hline Pressure in the head & $5(62.5)$ & $3(37.5)$ & $12(57.1)$ & $20(54.1)$ \\
\hline Sadness & $5(62.5)$ & $0(0)$ & $10(47.6)$ & $15(40.5)$ \\
\hline Sensitivity to light & $5(62.5)$ & $1(12.5)$ & $10(47.6)$ & $16(43.2)$ \\
\hline Sensitivity to noise & $5(62.5)$ & $3(37.5)$ & $12(57.1)$ & $20(54.1)$ \\
\hline Sleeping too little & $2(25.0)$ & $0(0)$ & $5(23.8)$ & $7(18.9)$ \\
\hline Sleeping too much & $1(12.5)$ & $0(0)$ & $5(23.8)$ & $6(16.2)$ \\
\hline Noise in the ears & $3(37.5)$ & $0(0)$ & $6(28.6)$ & $9(24.3)$ \\
\hline Vertigo & $4(50.0)$ & $0(0)$ & $5(23.8)$ & $9(24.3)$ \\
\hline Vision changes & $2(25.0)$ & $1(12.5)$ & $5(23.8)$ & $8(21.6)$ \\
\hline
\end{tabular}

PCS, post-concussion syndrome; DASS-42, Depression and Anxiety Stress Scale-42. 
Table 4. Comparison of Median DaSS-42 Depression, Anxiety, Stress, and Total Score According to Patient Sex, Mechanism of Injury, and Number of Previous Concussions

\begin{tabular}{|c|c|c|c|c|c|}
\hline & Variable & $\begin{array}{l}\text { DASS-42 depression } \\
\text { score (median [IQR]) }\end{array}$ & $\begin{array}{c}\text { DASS-42 anxiety score } \\
\text { (median [IQR]) }\end{array}$ & $\begin{array}{l}\text { DASS-42 stress score } \\
\text { (median [IQR]) }\end{array}$ & $\begin{array}{l}\text { DASS-42 total score } \\
\text { (median [IQR]) }\end{array}$ \\
\hline \multirow[t]{3}{*}{ Patient sex } & Male $(n=44)$ & $3.50[1.00,9.25]$ & $2[0.75,8.00]$ & $8.5[3.8,14.3]$ & $15[5.0,29.6]$ \\
\hline & Female $(n=61)$ & $2[0,11]$ & $4[1,8]$ & $10[6,19]$ & $18[8,39]$ \\
\hline & $p$ & 0.777 & 0.235 & 0.12 & 0.325 \\
\hline \multirow[t]{5}{*}{ Mechanism of injury } & Fall $(n=32)$ & $2[0,13]$ & $3[1.0,7.3]$ & $8.5[4.8,16.8]$ & $11.5[7.3,39.5]$ \\
\hline & $\operatorname{MVC}(n=12)$ & $3.5[1.0,10.3]$ & $3[2.0,6.5]$ & $11.5[4.3,15.3]$ & $17[12.5,30.5]$ \\
\hline & $S \& \mathrm{R}(n=42)$ & $3.5[0.0,9.8]$ & $4[1.5,7.0]$ & $11[3,18]$ & $18[6.5,36.4]$ \\
\hline & $\mathrm{SO}(n=19)$ & $3[1.0,4.5]$ & $4[1.5,7.0]$ & $11[3,18]$ & $19[6.5,28.8]$ \\
\hline & $p$ & 0.959 & 0.953 & 0.99 & 0.985 \\
\hline \multirow{4}{*}{$\begin{array}{l}\text { No. of previous } \\
\text { concussions }\end{array}$} & $0(n=40)$ & $1[0.0,3.3]$ & $2[0.0,5.3]$ & $6[2.0,11.5]$ & $9[3.0,19.5]$ \\
\hline & $1(n=1)$ & $4[0,8]$ & $3[2,8]$ & $13[6,18]$ & $20[9,43]$ \\
\hline & $2+(n=48)$ & $6.5[1.9,13.9]$ & $5[2.0,9.3]$ & $10.5[6.0,18.3]$ & $22[11.0,39.5]$ \\
\hline & $p$ & $0.018^{*}$ & $0.03 *$ & $0.01 *$ & $0.004 *$ \\
\hline
\end{tabular}

Distribution of median DASS-42 depression, anxiety, stress, and total score according to patient sex, mechanism of injury, and number of previous concussions.

There were no differences in median DASS-42 score according to patient sex in the DASS-42 depression $(p=0.78)$, anxiety $(p=0.24)$, and stress $(p=0.12)$ subscales, as well as DASS-42 total score $(p=0.33)$. Likewise, no differences in median DASS-42 score according to patient mechanism of injury were observed in the DASS-42 depression $(p=0.96)$, anxiety $(p=0.95)$, and stress $(p=0.99)$ subscales, as well as DASS-42 total score $(p=0.99)$.

*Increased number of previous concussions was correlated with an increased median DASS-42 score in the depression $(p=0.018)$, anxiety $(p=0.030)$, stress $(p=0.010)$ subscale domains, as well as overall DASS-42 total score $(p=0.004)$.

DASS-42, Depression and Anxiety Stress Scale-42; IQR, interquartile range; MVC, motor vehicle collision; S \& R, sports and recreation; SO, struck by object.

subscales (Table 4; Fig. 2), as well as DASS- $42^{35}$ total score $(p=0.004)$.

Tables 5 and 6 illustrate the distribution of patients in the normal, mild, moderate, severe, and extremely severe symptom range of the DASS $-42^{35}$ depression and anxiety subscales, respectively. Of the

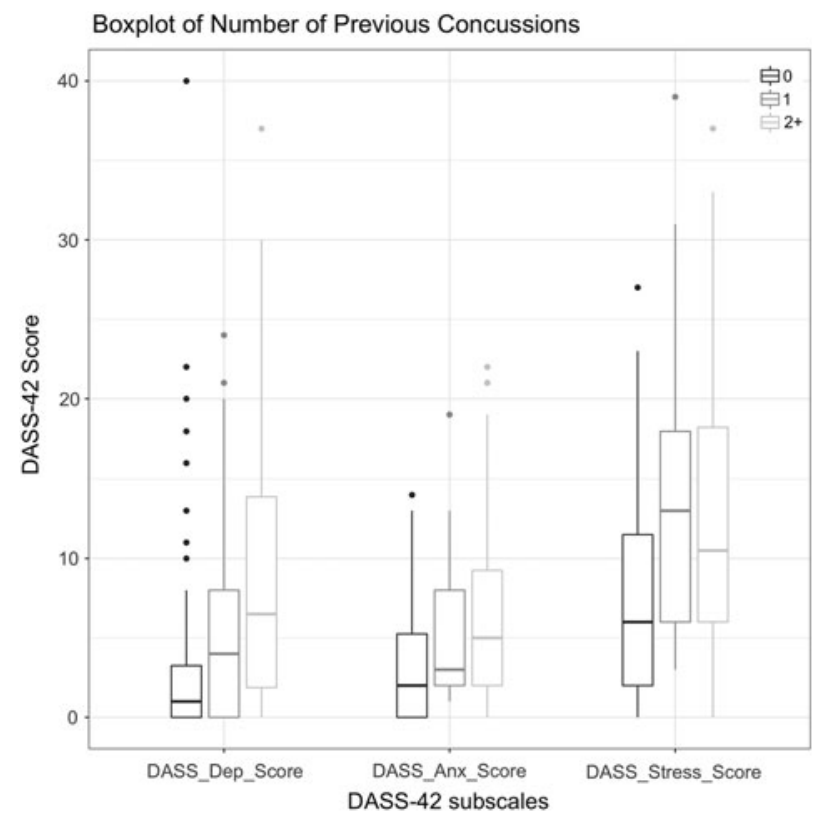

FIG. 2. Boxplot illustrating the relationship between number of previous concussions and DASS-42 anxiety, depression, and stress score. The top and bottom of each box represent the interquartile range (IQR). The solid line that traverses each box horizontally represents the median DASS-42 score for each subscale. An increased number of previous concussions is correlated with an increased DASS-42 score for each of the depression $(p=0.018)$, anxiety $(p=0.03)$, and stress $(p=0.01)$ subscales. DASS-42, Depression and Anxiety Stress Scale-42. total 105 patients, most scored in the normal range $(n=76 ; 72.4 \%)$ on the depression subscale, whereas most of the patients who scored above normal were clustered in the moderate severity of depression symptom range ( $n=13$ [12.4\%]; Table 5). We observed no differences in DASS- $42^{35}$ depression symptom severity according to patient age $(p=0.98)$, sex $(p=0.13)$, mechanism of injury $(p=0.15)$, and number of previous concussions $(p=0.58$; Table 5). Likewise, no differences were found in DASS- $42^{35}$ anxiety symptom severity according to patient age $(p=0.19)$, sex ( $p=0.76)$, mechanism of injury $(p=0.76)$, and number of previous concussions $(p=0.32$; Table 6). Of the total 105 patients, most scored in the normal range $(72.4 \%)$ on the anxiety subscale, whereas of the patients who scored above normal, most were clustered in the moderate severity anxiety symptom range $(n=13$ [12.4\%]; Table 6).

Table 7 compares patients who scored normal on the DASS- $42^{35}$ anxiety and depression subscales (no symptoms) with those who had clinically elevated symptoms of depression, anxiety, or both. We found no differences based on patient age $(p=0.58)$, sex $(p=0.64)$, mechanism of injury $(p=0.67)$, and number of previous concussions $(p=0.22)$ between the two groups. Table 8 compares patients who had clinically elevated symptoms of both depression and anxiety with patients who had clinically elevated symptoms of depression or anxiety alone. We found no differences between these two groups based on patient age $(p=0.305)$, sex $(p=0.705)$, mechanism of injury ( $p=0.337)$, and number of previous concussions $(p=0.808)$.

\section{World Health Organization Quality of Life Assessment-BREF outcomes}

The first two questions of the WHOQOL-BREF ${ }^{37}$ are not included as part of the WHOQOL-BREF ${ }^{37}$ score and provide a broad overview of patient satisfaction in relation to quality of life. The mean score of patient responses to question 1, "How would you rate your quality of life?" was $3.90 \pm 0.95$. The mean score of 
Table 5. Distribution of DASS-42 Depression Symptom Severity According to Patient Age, Sex, Mechanism of Injury, And Number of Previous Concussions ( $N=$ IO5)

\begin{tabular}{|c|c|c|c|c|c|c|c|}
\hline \multirow[b]{2}{*}{ Variable } & & \multicolumn{5}{|c|}{ DASS-42 Depression Symptom Severity Rating } & \multirow[b]{2}{*}{$\begin{array}{l}\text { Significance } \\
\mathrm{p} \text { value }\end{array}$} \\
\hline & & Normal & Mild & Moderate & Severe & $\begin{array}{l}\text { Extremely } \\
\text { severe }\end{array}$ & \\
\hline \multicolumn{2}{|l|}{ Current age, years, mean (SD) } & $38.6(15.9)$ & $41.7(12.8)$ & $39.5(13.6)$ & $38.8(12.8)$ & $41.0(16.8)$ & 0.98 \\
\hline \multirow[t]{2}{*}{ Patient sex, $n(\%)$} & Female $(n=61)$ & $43(70.5)$ & $6(9.8)$ & $5(8.2)$ & $3(4.9)$ & $4(6.6)$ & 0.13 \\
\hline & Male $(n=44)$ & $33(75.0)$ & $1(2.3)$ & $8(18.2)$ & $2(4.5)$ & $0(0)$ & \\
\hline \multirow[t]{4}{*}{ Mechanism of injury, $n(\%)$} & Fall $(n=32)$ & $23(71.9)$ & $2(6.3)$ & $4(12.5)$ & $0(0)$ & $3(9.4)$ & 0.15 \\
\hline & $\operatorname{MVC}(n=12)$ & $7(58.3)$ & $3(25.0)$ & $1(8.3)$ & $0(0)$ & $1(8.3)$ & \\
\hline & SO $(n=19)$ & $15(78.9)$ & $1(5.3)$ & $2(10.5)$ & $1(5.3)$ & $0(0)$ & \\
\hline & $\mathrm{S} \& \mathrm{R}(n=42)$ & $31(73.8)$ & $1(2.4)$ & $6(14.3)$ & $4(9.5)$ & $0(0)$ & \\
\hline \multirow{3}{*}{$\begin{array}{l}\text { No. of previous } \\
\text { concussions, } n(\%)\end{array}$} & $0(n=40)$ & $32(80.0)$ & $3(7.7)$ & $3(7.7)$ & $1(2.6)$ & $1(2.6)$ & 0.58 \\
\hline & $1(n=17)$ & $13(76.5)$ & $0(0)$ & $2(12.5)$ & $2(12.5)$ & $0(0)$ & \\
\hline & $2+(n=48)$ & $31(64.6)$ & $4(8.0)$ & $8(16.0)$ & $2(4.0)$ & $3(6.0)$ & \\
\hline Total $(n=105)$ & & $76(72.4)$ & $7(6.7)$ & $13(12.4)$ & $5(4.8)$ & $4(3.8)$ & - \\
\hline
\end{tabular}

Distribution of DASS-42 depression symptom severity according to patient age, sex, mechanism of injury, and number of previous concussions. No differences in depression symptom severity were found based on patient age $(p=0.98)$, sex $(p=0.13)$, mechanisms of injury $(p=0.15)$, or number of previous concussions $(p=0.58)$.

DASS-42, Depression and Anxiety Stress Scale-42; SD, standard deviation; MVC, motor vehicle collision; S \& R, sports and recreation; SO, strike by object.

patient responses to question 2, "How satisfied are you with your health?" was $3.19 \pm 1.20$. Table 9 illustrates the mean WHOQOL$\mathrm{BREF}^{37}$ score for each domain according to patient sex, mechanism of injury, and number of previous concussions. No differences in mean WHOQOL-BREF ${ }^{37}$ score were observed between male and female patients in the physical health $(p=0.484)$, psychological health ( $p=0.483)$, or environment ( $p=0.641)$ domains. However, we observed that the mean WHOQOL-BREF ${ }^{37}$ score in domain 3 (social relationships) was 9 points lower in females compared to males ( $p=0.083$; Table 9).

No differences were found in mean WHOQOL-BREF ${ }^{37}$ score in the physical health $(p=0.119)$ and psychological health ( $p=0.891)$ domains across mechanisms of injury. However, we observed a difference in mean WHOQOL-BREF ${ }^{37}$ score in the social relationships domain (domain 3) across mechanisms of injury $\left(F_{(3,96)}=3.572, p=0.017\right.$; Table 9$)$. More specifically, patients who sustained their concussion as a result of a motor vehicle collision (MVC) had lower mean WHOQOL-BREF ${ }^{37}$ social relationship domain scores in comparison to those who sustained their concussion as a result of a sports and recreation injury $(p=0.002)$ or fall $(p=0.04)$. Likewise, we observed a difference in mean WHOQOL-BREF ${ }^{37}$ score in the environment domain (domain 4) across mechanisms of injury $\left(F_{(3,96)}=3.761, p=0.0133\right.$; Table 9$)$. Patients who sustained their concussion as a result of an MVC had lower mean WHOQOL-BREF ${ }^{37}$ scores in the environment domain in comparison to those patients who acquired their concussion as a result of a fall $(p=0.038)$, object strike $(p=0.002)$, or through sports and recreation $(p=0.007)$.

No differences were observed in mean WHOQOL-BREF ${ }^{37}$ scores with respect to number of previous concussions in the physical health $(p=0.488)$, psychological health $(p=0.257)$, social relationships $(p=0.782)$, and environment $(p=0.670)$ domains (Table 9).

Table 6. Distribution of DASS-42 Anxiety Symptom Severity According to Patient Age, Sex, Mechanism of Injury, And Number of Previous Concussions $(N=105)$

\begin{tabular}{|c|c|c|c|c|c|c|c|}
\hline \multirow[b]{2}{*}{ Variable } & & \multicolumn{5}{|c|}{ DASS-42 anxiety symptom severity rating } & \multirow[b]{2}{*}{$\begin{array}{c}\text { Significance } \\
\text { p value }\end{array}$} \\
\hline & & Normal & Mild & Moderate & Severe & $\begin{array}{c}\text { Extremely } \\
\text { severe }\end{array}$ & \\
\hline \multicolumn{2}{|l|}{ Current age, years, mean (SD) } & $39.6(15.4)$ & $32.1(15.1)$ & $39.2(15.2)$ & $39.3(16.2)$ & $43.0(5.6)$ & 0.75 \\
\hline \multirow[t]{2}{*}{ Patient sex, $n(\%)$} & Female $(n=61)$ & $44(72.1)$ & $3(4.9)$ & $10(16.4)$ & $2(3.3)$ & $2(3.3)$ & 0.19 \\
\hline & Male $(n=44)$ & $32(72.7)$ & $5(11.4)$ & $3(6.8)$ & $4(9.1)$ & $0(0)$ & \\
\hline \multirow[t]{4}{*}{ Mechanism of injury, $n(\%)$} & Fall $(n=32)$ & $24(75.0)$ & $2(6.3)$ & $3(9.4)$ & $2(6.3)$ & $1(3.1)$ & 0.76 \\
\hline & $\operatorname{MVC}(n=12)$ & $9(75.0)$ & $0(0)$ & $2(16.7)$ & $1(8.3)$ & $0(0)$ & \\
\hline & $\mathrm{SO}(n=19)$ & $14(73.7)$ & $3(15.8)$ & $1(5.3)$ & $0(0)$ & $1(5.3)$ & \\
\hline & $\mathrm{S} \& \mathrm{R}(n=42)$ & $29(69.0)$ & $3(7.1)$ & 7 (16.7) & $3(7.1)$ & $0(0)$ & \\
\hline \multirow{3}{*}{ No. of previous concussions, $n(\%)$} & $0(n=40)$ & $33(82.5)$ & $2(5.1)$ & $5(12.8)$ & $0(0)$ & $0(0)$ & 0.32 \\
\hline & $1(n=17)$ & $12(70.6)$ & $1(6.3)$ & $3(18.8)$ & $1(6.3)$ & $0(0)$ & \\
\hline & $2+(n=48)$ & $31(64.6)$ & $5(10.0)$ & $5(10.0)$ & $5(10.0)$ & $2(4.0)$ & \\
\hline Total $(n=105)$ & & $76(72.4)$ & $8(7.6)$ & $13(12.4)$ & $6(5.7)$ & $2(1.9)$ & - \\
\hline
\end{tabular}

Distribution of DASS-42 anxiety symptom severity according to patient age, sex, mechanism of injury, and number of previous concussions. No differences in anxiety symptom severity were found based on patient age $(p=0.75)$, sex $(p=0.19)$, between males and mechanisms of injury $(p=0.76)$, or number of previous concussions $(p=0.32)$.

DASS-42, Depression and Anxiety Stress Scale-42; SD, standard deviation; MVC, motor vehicle collision; S \& R, sports and recreation, SO, strike by object. 
Table 7. Comparison of Patients with DASS-42 Symptoms of Anxiety, Depression, Both, or Neither According to Patient Age, Sex, Mechanism of Injury, Number of Previous Concussions and WHOQOL-BREF Mean Domain Score ( $N=$ I05)

\begin{tabular}{|c|c|c|c|c|c|}
\hline & & $\begin{array}{c}\text { Symptoms of } \\
\text { depression } \\
\text { and anxiety }(\mathrm{n}=21)\end{array}$ & $\begin{array}{c}\text { Symptoms of } \\
\text { depression } \\
\text { or anxiety }(\mathrm{n}=16)\end{array}$ & $\begin{array}{c}\text { No symptoms } \\
\text { of depression, } \\
\text { anxiety, or both } \\
(\mathrm{n}=68)\end{array}$ & $\mathrm{p}$ value \\
\hline \multicolumn{2}{|l|}{ Current age, years, mean (SD) } & $40.1(14.65)$ & $35.4(11.73)$ & $39.5(16.04)$ & 0.58 \\
\hline \multirow[t]{2}{*}{ Sex, $n(\%)$} & Female & $12(57.1)$ & $11(68.8)$ & $38(55.9)$ & 0.64 \\
\hline & Male & $9(42.9)$ & $5(31.2)$ & $30(44.1)$ & \\
\hline \multirow[t]{4}{*}{ Mechanism of injury, $n(\%)$} & MVC & $3(14.3)$ & $2912.5)$ & $7(10.3)$ & 0.67 \\
\hline & Fall & $6(28.6)$ & $5(31.2)$ & $21(30.9)$ & \\
\hline & $S \& R$ & $10(47.6)$ & $4(25.0)$ & $28(41.2)$ & \\
\hline & SO & $2(9.5)$ & $5(31.2)$ & $12(17.6)$ & \\
\hline \multirow{3}{*}{$\begin{array}{l}\text { No. of previous concussions, } \\
\quad n(\%)\end{array}$} & 0 & $6(28.6)$ & $3(18.8)$ & $31(45.6)$ & 0.22 \\
\hline & 1 & $3(14.3)$ & $3(18.8)$ & $11(16.2)$ & \\
\hline & $2+$ & $12(57.1)$ & $10(62.5)$ & $26(38.2)$ & \\
\hline \multirow{4}{*}{$\begin{array}{l}\text { WHOQOL-BREF score } \\
\text { mean }(\mathrm{SD} ; \mathrm{n}=100)\end{array}$} & Domain 1 (physical health) & $50.05(20.57)$ & $61.40(15.43)$ & $72.35(16.21)$ & $<0.001^{*}$ \\
\hline & Domain 2 (psychological health) & $40.45(15.97)$ & $52.60(17.05)$ & $71.82(15.70)$ & $<0.001 *$ \\
\hline & Domain 3 (social relationship) & $46.90(25.46)$ & $58.40(27.58)$ & $70.46(21.80)$ & $0.001 *$ \\
\hline & Domain 4 (environment) & $67.85(18.47)$ & $73.87(14.49)$ & $84.35(12.21)$ & $<0.001 *$ \\
\hline
\end{tabular}

No differences were found in the distribution of patients with symptoms of anxiety, depression, both, or neither according to patient sex, mechanism of injury, and number of previous concussions.

*Patients with symptoms of both depression and anxiety or depression or anxiety alone had lower mean WHOQOL-BREF scores in all four domains compared to patients with no symptoms of either depression or anxiety $(p<0.001)$.

${ }^{a}$ Mean WHOQOL-BREF scores were calculated on data from 100 patients, because of the exclusion of 5 patients from the total population because of incomplete data.

DASS-42, Depression and Anxiety Stress Scale-42; WHOQOL-BREF, World Health Organization Quality of Life-abbreviated version; SD, standard deviation; MVC, motor vehicle collision; S \& R, sports and recreation; SO, strike by object.

Table 8. Comparison of Patients with DASS-42 Symptoms of Depression and AnXiety Combined with Patients with Symptoms of Depression or Anxiety Alone $(N=37)$

\begin{tabular}{|c|c|c|c|c|}
\hline & & $\begin{array}{c}\text { Symptoms of } \\
\text { depression and } \\
\text { anxiety }(\mathrm{n}=21)\end{array}$ & $\begin{array}{c}\text { Symptoms of } \\
\text { depression or } \\
\text { anxiety }(\mathrm{n}=16)\end{array}$ & $\mathrm{p}$ value \\
\hline \multicolumn{2}{|c|}{ Current age, years, mean (SD) } & $40.1(14.65)$ & $35.4(11.73)$ & 0.305 \\
\hline \multirow[t]{2}{*}{ Sex, $n(\%)$} & Female & $12(57.1)$ & $11(68.8)$ & 0.705 \\
\hline & Male & $9(42.9)$ & $5(31.2)$ & \\
\hline \multirow{4}{*}{$\begin{array}{l}\text { Mechanism } \\
\quad \text { of injury, } n(\%)\end{array}$} & MVC & $3(14.3)$ & $2912.5)$ & 0.337 \\
\hline & Fall & $6(28.6)$ & $5(31.2)$ & \\
\hline & $S \& R$ & $10(47.6)$ & $4(25.0)$ & \\
\hline & $\mathrm{SO}$ & $2(9.5)$ & $5(31.2)$ & \\
\hline \multirow{3}{*}{$\begin{array}{l}\text { No. of previous } \\
\text { concussions, } n(\%)\end{array}$} & 0 & $6(28.6)$ & $3(18.8)$ & 0.808 \\
\hline & 1 & $3(14.3)$ & $3(18.8)$ & \\
\hline & $2+$ & $12(57.1)$ & $10(62.5)$ & \\
\hline \multirow{4}{*}{$\begin{array}{l}\text { WHOQOL-BREF score }{ }^{\mathrm{a}} \text {, } \\
\text { mean }(\mathrm{SD} ; n=100)\end{array}$} & Domain 1 (physical health) & $50.05(20.57)$ & $61.40(15.43)$ & 0.083 \\
\hline & Domain 2 (psychological health) & $40.45(15.97)$ & $52.60(17.05)$ & $0.038 *$ \\
\hline & Domain 3 (social relationship) & $46.90(25.46)$ & $58.40(27.58)$ & 0.211 \\
\hline & Domain 4 (environment) & $67.85(18.47)$ & $73.87(14.49)$ & 0.305 \\
\hline
\end{tabular}

No differences were found in the distribution of patients with combined symptoms of depression and anxiety and depression or anxiety alone according to patient age $(p=0.305)$, sex $(p=0.705)$, mechanism of injury $(p=0.337)$, number of previous concussions $(p=0.808)$, domain 3 mean WHOQOLBREF score $(p=0.211)$, and domain 4 mean WHOQOL-BREF score $(p=0.305)$.

Patients with symptoms of both depression and anxiety had lower mean WHOQOL-BREF scores in the physical health $(p=0.083)$ domain compared to patients with symptoms of depression alone or anxiety alone.

*Patients with symptoms of both depression and anxiety had lower mean WHOQOL-BREF scores in the psychological health $(p=0.038)$ domains compared to patients with symptoms of depression alone or symptoms of anxiety alone.

${ }^{a}$ Mean WHOQOL-BREF scores were calculated on data from 100 patients, because of the exclusion of 5 patients from the total population because of incomplete data.

DASS-42, Depression and Anxiety Stress Scale-42; SD, standard deviation; WHOQOL-BREF; World Health Organization Quality of Life-abbreviated version; MVC, motor vehicle collision; S \& R, sports and recreation; SO, strike by object. 
Table 9. Mean WhOQOL-BReF Score in Each Quality of Life Domain Categorized by Patient Sex, Mechanism of Injury, AND Number of Previous Concussions $(N=\mathrm{IOO})$

\begin{tabular}{|c|c|c|c|c|c|}
\hline & Variable & $\begin{array}{c}\text { Domain 1: } \\
\text { physical health } \\
\text { mean score }(S D)\end{array}$ & $\begin{array}{c}\text { Domain 2: } \\
\text { psychological health } \\
\text { mean score }(S D)\end{array}$ & $\begin{array}{c}\text { Domain } 3: \\
\text { social relationships } \\
\text { mean score }(S D)\end{array}$ & $\begin{array}{c}\text { Domain 4: } \\
\text { environment } \\
\text { mean score }(S D)\end{array}$ \\
\hline & $\begin{array}{l}\text { Respondent } \\
\quad \text { population }(n=100)\end{array}$ & $66.25(19.13)$ & $62.66(20.48)$ & $63.94(25.11)$ & $79.48(15.47)$ \\
\hline \multirow[t]{3}{*}{ Patient sex } & Female $(n=58)$ & $65.10(18.81)$ & $61.43(21.66)$ & $60.24(27.19)$ & $78.86(17.10)$ \\
\hline & Male $(n=42)$ & 67.83 (19.67) & $64.36(62.22)$ & $69.04(21.17)$ & 80.33 (13.03) \\
\hline & $p$ & 0.484 & 0.483 & 0.083 & 0.641 \\
\hline \multirow{5}{*}{$\begin{array}{l}\text { Mechanism } \\
\text { of injury }\end{array}$} & Fall $(n=32)$ & $62.50(18.53)$ & $62.70(21.64)$ & $63.00(27.92)$ & $78.20(17.22)$ \\
\hline & $\operatorname{MVC}(n=12)$ & $57.64(16.26)$ & $58.55(18.84)$ & $45.36(20.44)$ & $67.18(19.83)$ \\
\hline & $\mathrm{S} \& \mathrm{R}(n=42)$ & $70.83(17.83)$ & $62.83(19.71)$ & $71.12(20.25)$ & 81.07 (12.39) \\
\hline & $\mathrm{SO}(n=19)$ & $67.12(22.98)$ & $64.82(22.63)$ & $59.88(28.02)$ & $85.76(12.15)$ \\
\hline & $p$ & 0.119 & 0.891 & $0.017 *$ & $0.013 *$ \\
\hline \multirow{4}{*}{$\begin{array}{l}\text { No. of previous } \\
\text { concussions }\end{array}$} & $0(n=37)$ & $69.24(22.20)$ & $67.00(20.26)$ & $62.00(26.70)$ & 77.68 (18.62) \\
\hline & $1(n=16)$ & $65.00(15.76)$ & $61.50(23.37)$ & $67.19(25.41)$ & $80.94(14.58)$ \\
\hline & $2+(n=47)$ & $64.32(17.58)$ & $59.64(19.45)$ & $64.36(24.12)$ & $80.40(13.03)$ \\
\hline & $p$ & 0.488 & 0.257 & 0.782 & 0.670 \\
\hline
\end{tabular}

No differences were observed between mean WHOQOL-BREF domain scores based on patient sex or number of previous concussions.

*A difference in mean WHOQOL-BREF score across mechanisms of injury was found in the social relationships $(p=0.017)$ and environment ( $p=0.013$ ) domains. Mean social relationship domain WHOQOL-BREF score was lower for patients who acquired their concussion as a result of a motor vehicle collision compared to a fall $(p=0.04)$ or as a result of a sports and recreation injury $(p=0.002)$. No differences were observed between patients who acquired their concussion as a result of a motor vehicle collision and object strike in the social relationship domain $(p=0.12)$. Mean WHOQOLBREF score was lower for patients who acquired their concussion as a result of a motor vehicle collision compared to a fall ( $p=0.038$ ), sports and recreation injury $(p=0.0069)$, and strike by object $(p=0.0016)$ in the environment domain.

WHOQOL-BREF, World Health Organization Quality of Life-abbreviated version; SD, standard deviation; MVC, motor vehicle collision; S \& R, sports and recreation; SO, strike by object.

\section{Relationship between Depression and Anxiety Stress Scale-42 score and quality of life}

We conducted a Spearman correlation between total DASS $-42^{35}$ score and mean WHOQOL-BREF ${ }^{37}$ score, and found a statistically significant correlation between elevated total DASS $-42^{35}$ score and a poorer overall QOL $(n=100, r=-0.655 ; p<0.001)$. The relationship between total DASS- $42^{35}$ score and mean QOL score is shown in Figure 3. Table 7 shows a comparison of patients who had clinically elevated symptoms of depression or anxiety $(n=16)$, both depression and anxiety $(n=21)$, or neither $(n=68)$ in relation to mean WHOQOL-BREF ${ }^{37}$ score in each domain. Patients who had symptoms of both depression and anxiety, or anxiety or depression alone, had lower mean WHOQOL-BREF ${ }^{37}$ scores in comparison to patients who had no symptoms of depression or anxiety $(p<0.001)$ in all four WHOQOL-BREF ${ }^{37}$ domains (Table 7). When comparing patients who had both symptoms of depression and anxiety $(n=21)$ with those who had symptoms of only depression $(n=8)$ or only anxiety $(n=8)$, we found that patients with symptoms of both depression and anxiety had a mean WHOQOL-BREF ${ }^{37}$ score $\sim 10$ points lower than those who had either symptoms of depression alone $(n=8)$ or anxiety alone $(n=8)$ in the physical health domain $(p=0.083$; Table 8).

Similarly, patients with symptoms of both depression and anxiety had a mean WHOQOL-BREF ${ }^{37}$ score $\sim 10$ points lower than those who had either symptoms of depression alone $(n=8)$ or anxiety alone $(n=8)$ in the psychological health domain ( $p=0.038)$. We observed no difference between these two groups for the social relationship ( $p=0.211)$ and environment $(p=0.305)$ WHOQOL-Bref ${ }^{37}$ domains. Figure 4 illustrates a correlation matrix between each of the DASS $-42^{35}$ depression, anxiety, and stress subscales as well as DASS- $42^{35}$ total score and WHOQOL-BREF ${ }^{37}$ domain scores. Increased DASS- $42^{35}$ depression subscale score was correlated with a poorer WHOQOL-BREF ${ }^{37}$ score in the psychological health domain ( $r=-0.72$; Fig. 4A). Increased DASS$42^{35}$ anxiety subscale score was correlated with a poorer WHOQOL-BREF ${ }^{37}$ score in the psychological health domain $\left(r=-0.62\right.$; Fig. 4B). Increased total DASS- $42^{35}$ score was correlated with a poorer WHOQOL-BREF ${ }^{37}$ score in the psychological health domain ( $r=-0.71$; Fig. $4 \mathrm{C}$ ).

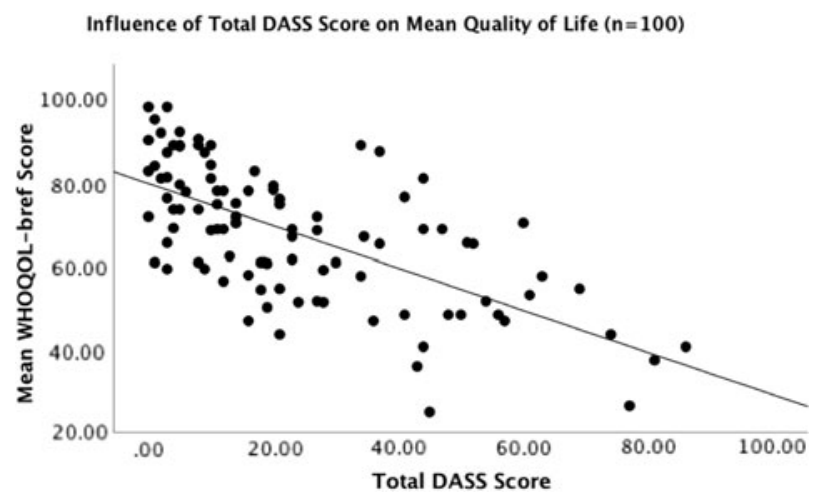

FIG. 3. Scatterplot illustrating the correlation between total DASS-42 score on mean overall WHOQOL-BREF score in 100 PCS patients. Total DASS-42 score was calculated through the summation of each of the depression, anxiety, and stress domain scores for each participant. Mean overall WHOQOL-BREF score was calculated by averaging the total score in each of the four respective quality-of-life domains (physical health, psychological health, social relationships, and environment) for each respondent. Elevated DASS-42 score was found to be a significant, unique predictor of poorer quality of life $\left(R^{2}=0.429, F_{(1,99)}=73.54\right.$, $p<0.0001, r=-0.655)$ in this PCS patient population. DASS-42, Depression and Anxiety Stress Scale-42; WHOQOL-BREF, World Health Organization Quality of Life Assessment-BREF. 


\section{Discussion}

To our knowledge, this is the first study to measure the relationship between symptoms of mood disorders and QOL in a large sample of adults suffering from PCS in Canada. Thirty-five percent $(n=37)$ of respondents endorsed elevated symptoms of depression, anxiety, or both as measured by the DASS $-42,{ }^{35}$ consistent with other estimates of depression (11-44\%) and anxiety (54\%) prevalence in PCS samples. ${ }^{42,43}$ The variation in prevalence may be related to differences in study population, setting, timing of recruitment, and the types of assessment measures used. ${ }^{44}$ Other factors cited that contribute to depression include being female, lower household income, low educational attainment, unemployment, and social isolation in older populations. ${ }^{45}$ However, in this study, we focused only on demographic factors such as age and sex. Additionally, because $76 \%$ of respondents in our study were still experiencing symptoms of PCS at the time of completing their questionnaires, it is likely that the prevalence of symptoms of depression and anxiety is on the higher end of the spectrum because of a respondent bias toward patients who have not recovered. We found a correlation between the number of previous concussions and an elevated DASS $-42^{35}$ depression and anxiety subscale score.

Other studies have also found a relationship between multiple concussions and elevations in symptoms of depression in PCS patients, ${ }^{25,46,47}$ indicating that preventing multiple concussions should be a public health concern given that it may mitigate the development of mood disorders in PCS patients.

The mechanism of injury may play a role in the QOL rating for PCS patients. Significant differences in mean WHOQOL-BREF ${ }^{37}$ scores were found in the social relationship domain between patients who acquired their concussion as a result of an MVC in comparison to those who sustained their concussion through sports and recreation or a fall. Likewise, significant differences were found in mean WHOQOL-BREF ${ }^{37}$ score in the environment domain between patients with MVC injuries and those who acquired their concussion as a result of being struck by an object, a fall, or sports and recreation injuries. Respondents who acquired a concussion as a result of an MVC scored, on average, 15 points lower in the social relationship and environment domain, in comparison to those with other mechanisms of injury. However, caution needs to be taken when interpreting results pertaining to MVCs given that many other factors, such as fault, trauma, and severity of other nonconcussion injuries, may influence QOL in these patients.

We found that elevated total DASS $-42^{35}$ score correlated with a poorer QOL in PCS patients. The total DASS- $42^{35}$ score is a measure of overall distress attributable to symptoms of anxiety, depression, and stress, and as it increased, the mean WHOQOL$\mathrm{BREF}^{37}$ QOL score decreased. Additionally, patients experiencing combined symptoms of depression and anxiety exhibited a lower mean WHOQOL-BREF ${ }^{37}$ score in the physical and psychological

FIG. 4. Simple scatterplot correlation matrix outlining the relationship between DASS-42 score and WHOQOL-BREF score. (A) Increased DASS-42 depression subscale score was correlated with a poorer WHOQOL-BREF score in the psychological health domain $(r=0.72)$. (B) Increased DASS-42 anxiety subscale score was correlated with a poorer WHOQOL-BREF score in the psychological health domain $(r=0.62)$. (C) Increased total DASS-42 score was correlated with a poorer WHOQOL-BREF score in the psychological health domain $(r=0.71)$. DASS-42, Depression and Anxiety Stress Scale-42; WHOQOL-BREF, World Health Organization Quality of Life Assessment-BREF.
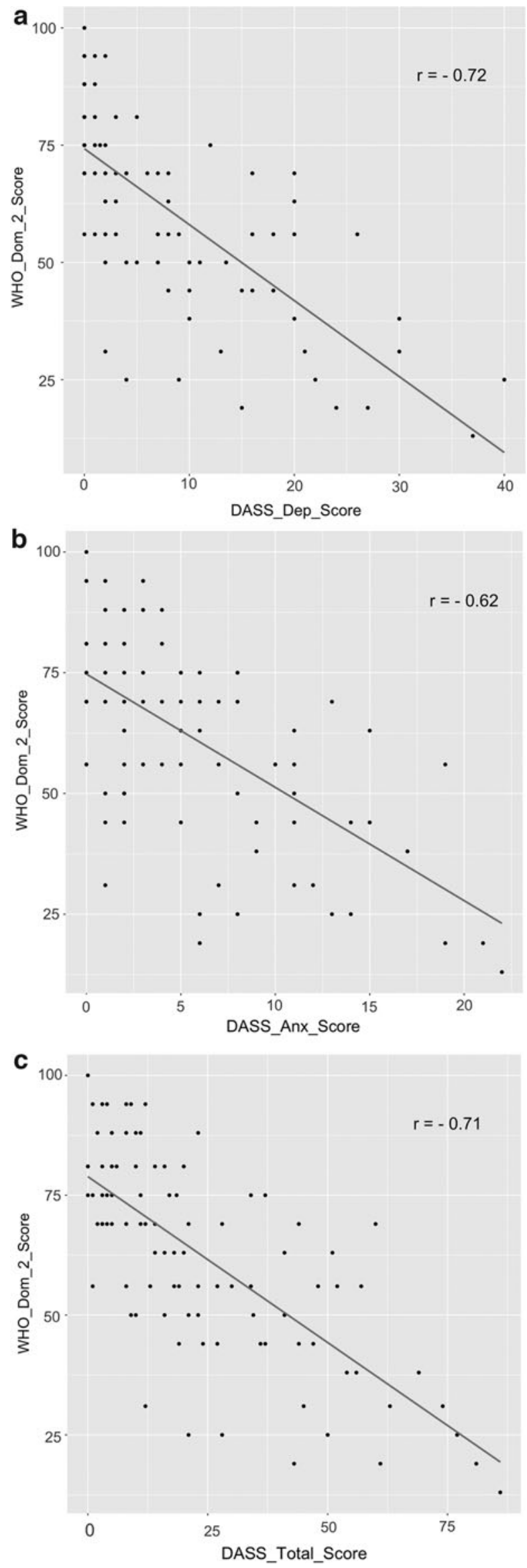
health domains in comparison to those who endorsed one or the other, suggesting that combined symptoms of depression and anxiety may exacerbate the negative effects of mood disorders on QOL in PCS patients. Because of limited previous studies of QOL in PCS patients, especially those with symptoms of depression and anxiety, there are only a small number of studies available for comparison. For example, Reddy and colleagues found that WHOQOL-BREF ${ }^{37}$ scores were negatively correlated with PCS symptoms, as well as diminished cognitive functioning. ${ }^{48}$

Another study examining health-related QOL measures confirms our findings that depression and anxiety are common in PCS and are associated with a considerable decrease in functional outcomes and health-related QOL. ${ }^{49}$ Additionally, health-related QOL assessments of PCS patients in the Netherlands have shown that PCS patients have lower health-related QOL scores, compared to concussion patients without $\mathrm{PCS},{ }^{32}$ and concussion patients in general exhibit lower SF-36 scores compared to Dutch population norms. ${ }^{34}$ Poorer QOL has also been observed in pediatric patients, with lower social, emotional, physical, and school QOL for at least 12 weeks after concussion. ${ }^{33}$ We have shown that patients with elevated DASS- $42^{35}$ scores experience a poorer QOL, which may not resolve for years post-injury.

Currently, little is known about the relationship between mood disorders, PCS, and QOL, which is an important factor in developing a comprehensive post-concussive evaluation that encompasses whole-person health. ${ }^{50}$ QOL measures have become increasingly important in the treatment of patients with chronic disease, including those with PCS. ${ }^{51}$ In our view, measurement of QOL should become standard practice in PCS, given that QOL measures can be used to form the framework for future research, assess the effectiveness of interventions, distinguish specific subsets of patients within a population, and develop treatment plans using a patient-centered approach. ${ }^{51}$ Perhaps, increasing access to treatment that is structured around the many facets of QOL during recovery from PCS can improve QOL for PCS patients, as well as address the issues of pain management, working capacity, dependence on medication, and access to healthcare and social care. In the future, QOL measures should be incorporated into the treatment and research in PCS to improve intervention strategies and enhance understanding of the trajectory of recovery in this population.

\section{Conclusions}

This study advances knowledge regarding the interaction between symptoms of depression, anxiety, stress, and QOL in PCS patients. It illustrates that a considerable number of PCS patients continue to suffer with symptoms of depression and anxiety for many years post-injury. PCS is a debilitating condition for which there is a paucity of effective treatment strategies. PCS patients find it difficult to return to their previous level of functioning. As we have shown, PCS significantly affects QOL, especially for those with symptoms of depression and anxiety, whereas the paucity of definitive treatments leaves patients suffering for years, or indefinitely.

\section{Limitations}

The patients in this study were all recruited from the CCC, a major urban clinic, which attracts patients who do not recover rapidly from concussion, and thus do not represent all concussion patients. It is likely that more complicated and persistent cases of PCS are referred to this Centre, often because of the longer wait times likely accounting for patients having seen multiple specialists before being seen at our centre. Also, all patients were referred to and examined by only one specialist. Moreover, this study most likely had a response bias toward patients who have not recovered, given that $76 \%$ of respondents self-reported still experiencing PCS symptoms. Thus, the results of this study may not be representative of the general population of PCS patients.

Moreover, significant differences were observed between the eligible and respondent population of PCS patients in relation to age and mechanism of injury. Accordingly, any results pertaining to mechanism of injury and age may not be representative of the total eligible population. We received fewer questionnaires from patients involved in MVCs, compared to other mechanisms of injury, most likely attributable to the fact that respondents with MVC injuries are often involved in litigation and would have been excluded from the population or did not respond on the basis of legal advice. Moreover, a response bias related to age was observed, with the average respondent age being 3 years older than that of the eligible population.

Despite these limitations, this is the first study to examine the relationship between WHOQOL-BREF scores and DASS- $42^{35}$ scores in a large Canadian population with persisting symptoms of concussion. We were able to confirm the results of other studies with respect to the relationship between number of previous concussions and depression and anxiety in PCS. Further, we used a definition of concussion that excluded patients with other serious brain injuries, such as hemorrhage or lesions, which would have been included if eligibility was based on the definition of mild traumatic brain injury. This was done to ensure that study participants had a diagnosis of concussion that was not confounded by other neurological and focal deficits that are included in the definition of mild traumatic brain injury.

\section{Acknowledgments}

The authors thank Ms. Mozhgan Khodadadi of the Canadian Concussion Center for her assistance with this study.

\section{Funding Information}

This study was funded by the Canadian Concussion Center, which is funded by the Toronto General and Toronto Western Hospital Foundation. The Toronto General and Toronto Western Hospital Foundation had no role in the design of this study and collection, analysis, interpretation of data, and writing of the manuscript.

\section{Author Disclosure Statement}

No competing financial interests exist.

\section{References}

1. Tator, C., Tartaglia, M., Ebraheem, A., Davis, K., Hiploylee, C., and Davis, H. (2016). Postconcussion syndrome: demography and predictors in 221 patients. J. Neurosurg. 125, 1206-1216.

2. Hiploylee, C., Dufort, P.A., Davis, H.S., Wennberg, R., Tartaglia, M.C., Mikulis, D., Hazrati, L., and Tator, C.H. (2017). Longitudinal study of postconcussion syndrome: not everyone recovers. J. Neurotrauma 34, 1511-1523.

3. Iverson, G.L., Gardner, A.J., Terry, D.P., Ponsford, J.L., Sills, A.K., Broshek, D.K., and Solomon, G.S. (2017). Predictors of clinical recovery from concussion: a systematic review. Br. J. Sport Med. 51, 941-948.

4. Iverson, G.L. (2005). Outcome from mild traumatic brain injury.Curr. Opin. Psychiatry 18, 301-317. 
5. Bazarian, J.J., and Atabaki, S. (2001). Predicting postconcussion syndrome after minor traumatic brain injury. Acad. Emerg. Med. 8 , 788-795

6. Jotwani, V., Harmon, KG. (2010). Postconcussion syndrome in athletes. Curr. Sports Med. Rep. 9, 21-26.

7. Prigatano, G.P., and Gale, S.D. (2011). The current status of postconcussion syndrome. Curr. Opin. Psychiatry 24, 243-250.

8. World Health Organization. (1992). ICD-10 Classification of Mental and Behavioral Disorders: Clinical Descriptions and Diagnostic Guidelines. World Health Organization: Geneva, Switzerland.

9. American Psychiatric Association. (1994). Diagnostic and Statistical Manual of Mental Disorders, 4th ed. American Psychiatric Association: Seattle, WA.

10. American Psychiatric Association. (2013). Diagnostic and Statistical Manual of Mental Disorders, 5th ed. American Psyciatric Publishing: Arlington, VA.

11. McCrory, P., Meeuwisse, W., Dvořák, J., Aubry, M., Bailes, J., Broglio, S., Cantu, R.C., Cassidy, D., Echemendia, R.J., Castellani, R.J., Davis, G.A., Ellenbogen, R., Emery, C., Engebretsen, L., Feddermann-Demont, N., Giza, C.C., Guskiewicz, K.M., Herring, S., Iverson, G.L., Johnston, K.M., Kissick, J.M., Kutcher, J., Leddy, J.J., Maddocks, D., Makdissi, M., Manley, G.T., McCrea, M., Meehan, W.P., Nagahiro, S., Patricios, J., Putukian, M., Schneider, K.J., Sills, A., Tator, C.H., Turner, M., and Vos, P.E. (2016). Consensus statement on concussion in sport-the 5th International Conference on Concussion in Sport held in Berlin. Br. J. Sports Med. $51,838-847$.

12. Ansari, A., Jain, A., Sharma, A., Mittal, R.S., and Gupta, I.D. (2014). Role of sertraline in posttraumatic brain injury depression and qualityof-life in TBI. Asian J. Neurosurg. 9, 182-188.

13. Vargas, G., Rabinowitz, A., Meyer, J., and Arnett, P.A. (2015). Predictors and prevalence of postconcussion depression symptoms in collegiate athletes. J. Athl. Train. 50, 250-255.

14. Rapoport, M.J., Mccullagh, S., Streiner, D., and Feinstein, A. (2003). The clinical significance of major depression following mild traumatic brain injury. Psychosomatics 44, 31-37.

15. Jorge, R.E., Robinson, R.G., Arndt, S.V., Starkstein, S.E., Forrester, A.W., and Geisler, F. (1993). Depression following traumatic brain injury: a 1 year longitudinal study. J. Affect. Disord. 27, 233-243.

16. Busch, C.R., and Alpern, H.P. (1998). Depression after mild traumatic brain injury: a review of current research. Neuropsychol. Rev. 8, 95108.

17. Fisher, L.B., Thomas, G., Mace, R.A., and Zafonte, R. (2019). Depression after traumatic brain injury, in: The Massachusetts General Hospital Guide to Depression. Springer International: Cham, Switzerland, pps. 87-105.

18. Gould, K.R., Ponsford, J.L., and Gershon, S. (2014). Association between cognitive impairments and anxiety disorders following traumatic brain injury. J. Clin. Exp. Neuropsychol. 36, 1-14.

19. Moore, E.L., Terryberry-Spohr, L., and Hope, D.A. (2006). Mild traumatic brain injury and anxiety sequelae: a review of the literature. Brain Inj. 20, 117-132.

20. Polinder, S., Cnossen, M.C., Real, R.G.L., Covic, A., Gorbunova, A., Voormolen, D.C., Master, C.L., Haagsma, J.A., Diaz-Arrastia, R., and von Steinbuechel, N. (2018). A multidimensional approach to postconcussion symptoms in mild traumatic brain injury. Front. Neurol. 9 , 1113.

21. Whelan-Goodinson, R., Ponsford, J.L., Schönberger, M., and Johnston, L. (2010). Predictors of psychiatric disorders following traumatic brain injury. J. Head Trauma Rehabil. 25, 320-329.

22. Albrecht, J.S., Barbour, L., Abariga, S.A., Rao, V., and Perfetto, E.M. (2019). Risk of depression after traumatic brain injury in a large national sample. J. Neurotrauma 36, 300-307.

23. Cnossen, M.C., Scholten, A.C., Lingsma, H.F., Synnot, A., Haagsma, J., Steyerberg, E.W., and Polinder, S. (2017). Predictors of major depression and posttraumatic stress disorder following traumatic brain injury: a systematic review and meta-analysis. J. Neuropsychiatry Clin. Neurosci. 29, 206-224.

24. Altemus, M., Sarvaiya, N., and Epperson, C.N. (2014). Sex differences in anxiety and depression clinical perspectives. Front. Neuroendocrinol. 35, 320-330.

25. Guskiewicz, K.M., and Broglio, S.P. (2015). Acute sports-related traumatic brain injury and repetitive concussion. Handb. Clin. Neurol. 127, 157-172.
26. Gould, K.R., Ponsford, J.L., Johnston, L., and Schönberger M. (2011) Predictive and associated factors of psychiatric disorders after traumatic brain injury: a prospective study. J Neurotrauma, 28(7), 1155 1163.

27. Senathi-Raja, D., Ponsford, J., Schönberger, M. (2010). The association of age and time postinjury with long-term emotional outcome following traumatic brain injury. J. Head Trauma Rehabil. 25, 330338.

28. Ashman, T.A., Spielman, L.A., Hibbard, M.R., Silver, J.M., Chandna, T., and Gordon, W.A. (2004). Psychiatric challenges in the first 6 years after traumatic brain injury: cross-sequential analyses of Axis I disorders. Arch. Phys. Med. Rehabil. 85, 4 Suppl. 2, 36-42.

29. Hibbard, M.R., Uysal, S., Kepler, K., Bogdany, J., and Silver, J. (1998). Axis I psychopathology in individuals with traumatic brain injury. J. Head Trauma Rehabil. 13, 24-39.

30. Fralick, M., Thiruchelvam, D., Tien, H.C., and Redelmeier, D.A. (2016). Risk of suicide after a concussion. CMAJ 188, 497-504.

31. Chisholm, D., Sweeny, K., Sheehan, P., Rasmussen, B., Smit, F., Cuijpers, P., and Saxena, S. (2016). Scaling-up treatment of depression and anxiety: a global return on investment analysis. Lancet Psychiatry 3, 415-424.

32. Voormolen, D.C., Polinder, S., von Steinbuechel, N., Vos, P.E., Cnossen, M.C., and Haagsma, J.A. (2019). The association between post-concussion symptoms and health-related quality of life in patients with mild traumatic brain injury. Injury 50, 1068-1074.

33. Novak, Z., Aglipay, M., Barrowman, N., Yeates, K.O., Beauchamp, M.H., Gravel, J., Freedman, S.B., Gagnon, I., Gioia, G., Boutis, K., Burns, E., Ledoux, A.A., Osmond, M.H., and Zemek, R.L. (2016). Association of persistent postconcussion symptoms with pediatric quality of life. JAMA Pediatr. 170, e162900.

34. Emanuelson, I., Andersson Holmkvist, E., Bjorklund, R., and Stalhammar, D. (2003). Quality of life and post-concussion symptoms in adults after mild traumatic brain injury: a population-based study in western Sweden. Acta Neurol. Scand. 108, 332-338.

35. Lovibond, P.F., and Lovibond, S.H. (1995). The structure of negative emotional states: Comparison of the Depression Anxiety Stress Scales (DASS) with the Beck Depression and Anxiety Inventories. Behav. Res. Ther. 33, 335-343.

36. Feinstein, A., Ouchterlony, D., Somerville, J., and Jardine, A. (2001). The effects of litigation on symptom expression: a prospective study following mild traumatic brain injury. Med. Sci. Law 41, 116-121.

37. World Health Organization, Division of Mental Health. (1996) WHOQOL-BREF: introduction, administration, scoring and generic version of the assessment: field trial version, December 1996. apps .who.int/iris/handle/10665/63529 (Last accessed September 29, 2020).

38. Wong, D., Dahm, J., and Ponsford, J. (2013). Factor structure of the depression anxiety stress scales in individuals with traumatic brain injury. Brain Inj. 27, 1377-1382.

39. Clark, L.A., and Watson, D. (1991). Tripartite model of anxiety and depression: psychometric evidence and taxonomic implications. J. Abnorm. Psychol. 100, 316-336.

40. Parkitny, L., and McAuley, J. (2010). The Depression Anxiety Stress Scale (DASS). J. Physiother. 56, 204.

41. Skevington, S.M., Lotfy, M., and O'Connell, K.A. (2004). The World Health Organization's WHOQOL-BREF quality of life assessment: psychometric properties and results of the international field trial. A report from the WHOQOL Group. Qual. Life Res. 13, 299-310.

42. Broshek, D.K., De Marco, A.P., and Freeman, J.R. (2015). A review of post-concussion syndrome and psychological factors associated with concussion. Brain Inj. 29, 228-237.

43. Dwyer, B., and Katz, D.I. (2018). Postconcussion syndrome. Sports Neurol. 158, 163-178.

44. Balakrishnan, B., Rus, R.M., Chan, K.H., Martin, A.G., and Awang, M.S. (2019). Prevalence of postconcussion syndrome after mild traumatic brain injury in young adults from a single neurosurgical center in east coast of malaysia. Asian J. Neurosurg. 14, 201-205.

45. Allen, J., Balfour, R., Bell, R., and Marmot, M. (2014). Social determinants of mental health. Int. Rev. Psychiatry 26, 392-407.

46. Kerr, Z.Y., Marshall, S.W., Harding, H.P., and Guskiewicz, K.M. (2012). Nine-year risk of depression diagnosis increases with increasing self-reported concussions in retired professional football players. Am. J. Sports Med. 40, 2206-2212. 
47. Guskiewicz, K.M., Marshall, S.W., Bailes, J., McCrea, M., Harding, H.P., Jr., Matthews, A., Mihalik, J.R., and Cantu, R.C. (2007). Recurrent concussion and risk of depression in retired professional football players. Med. Sci. Sports Exerc. 39, 903-909.

48. Reddy, R.P., Rajeswaran, J., Devi, B.I., and Kandavel, T. (2017). Cascade of traumatic brain injury: a correlational study of cognition, postconcussion symptoms, and quality of life. Indian J. Psychol. Med. $39,32-39$.

49. Haagsma, J.A., Scholten, A.C., Andriessen, T.M.J.C., Vos, P.E., Van Beeck, E.F., and Polinder, S. (2015). Impact of depression and posttraumatic stress disorder on functional outcome and health-related quality of life of patients with mild traumatic brain injury. J. Neurotrauma 32, 853-862.

50. Houston, M.N., Bay, R.C., and Valovich McLeod, T.C. (2016). The relationship between post-injury measures of cognition, balance, symptom reports and health-related quality-of-life in adolescent athletes with concussion. Brain Inj. 30, 891-898.
51. van Ierssel, J., Sveistrup, H., and Marshall, S. (2018). Identifying the concepts contained within health-related quality of life outcome measures in concussion research using the International Classification of Functioning, Disability, and Health as a reference: a systematic review. Qual. Life Res. 27, 3071-3086.

Address correspondence to:

Charles H. Tator, $M D, P h D$

University Health Network-TWH

399 Bathurst Street

Room 4W-433

Toronto, Ontario M5T 2S8

Canada

E-mail: charles.tator@uhn.ca 